\title{
D. E. Wilson and R. A. Mittermeier (chief editors): Handbook of the Mammals of the World. Vol. 9. Bats.
}

\author{
Lynx Edicions, Barcelona (2019). 1008 pp., 74 colour plates, 404 colour photographs, 1422 \\ distribution maps. Hardback. €160, ISBN: 978-84-16,728-19-0
}

\author{
Frank E. Zachos ${ }^{1,2}$
}

Published online: 8 April 2020

() Deutsche Gesellschaft für Säugetierkunde 2020

\begin{abstract}
All good things must come to an end. The last volume of the Handbook of the Mammals of the World is on bats (Chiroptera), and with more than 1400 species covered it is another truly Herculean task. So much so that the references (more than 8000 of them!) did not fit within the printed book but can be downloaded online, along with an illustrated overview of bat "families". Apart from being available online, the references also come on a CD-ROM that is delivered with the book. Limited space is probably also the reason why there are no introductory chapters (some of which were very informative in the preceding volumes). There is a very short Introduction which is more like a preface with acknowledgements, and in it, we learn that the sequence of "families" follows the latest insights into chiropteran phylogenetics, i.e. most importantly, it mirrors the deepest split between what is called Yinpterochiroptera and Yangochiroptera (rather than the outdated dichotomy between pteropodids, or fruit bats, and all other groups). That is much appreciated because, in spite of my general enthusiasm for the Handbook series, phylogenetics has not been its strong suit. The wildlife photography is once more superb, even though the present volume undoubtedly covers the mammalian group most difficult to get good pictures of.

The species chapters are short, for space reasons but perhaps also because there is not necessarily a lot of information on every single tropical species available. There are bat-specific measurements (e.g. forearm length), and there
\end{abstract}

Frank E. Zachos

frank.zachos@nhm-wien.ac.at

1 Natural History Museum Vienna, Vienna, Austria

2 Department of Genetics, University of the Free State, Bloemfontein, South Africa is also valuable bioacoustic information on call frequencies, call durations and interpulse intervals. For a current research project, we were interested in flight modes of different groups, and we were often very pleased with the information we found. Since many species look very similar externally, highlighting differences between closely related species in the plates would have been welcome, but perhaps difficult to do. The overall impression of this book is that it is another formidable achievement, and it is indeed astonishing and admirable that the quality of the different Handbook volumes is not only high but also consistently so. In any case, there is no longer a reason to be envious of our ornithologist colleagues-mammalogists now have a complete and equally good Handbook of their own. And who knows, maybe there will even be a tenth volume, an illustrated checklist (which has also been published for birds). Ten years after the publication of the first mammal Handbook volume, it is certainly not too soon for an update. Either way, the editors and the countless authors of all nine volumes deserve respect and gratitude for this series which will be the standard reference for years, if not decades, to come.

Publisher's Note Springer Nature remains neutral with regard to jurisdictional claims in published maps and institutional affiliations. 